\title{
Muscleblind-Like Proteins
}

\section{Similarities and Differences in Normal and Myotonic Dystrophy Muscle}

Ian Holt, ${ }^{\star \dagger}$ Virginie Jacquemin, ${ }^{\ddagger}$ Majid Fardaei, ${ }^{\S}$ Caroline A. Sewry, ${ }^{*}$ Gillian S. Butler-Browne, ${ }^{\neq}$ Denis Furling, ${ }^{\ddagger}$ J. David Brook, and Glenn E. Morris* ${ }^{* \dagger}$

From the Wolfson Centre for Inherited Neuromuscular Disease," RJAH Orthopaedic Hospital, Oswestry, Shropshire, United Kingdom, the Institute for Science and Technology in Medicine, ${ }^{\dagger}$ Keele University, United Kingdom, Universite Pierre et Marie Curie ${ }^{\ddagger}$ and Unite Mixt de Researche en Sante 787, Institute de Myologie, Paris, France; the Institute of Genetics, ${ }^{\S}$ University of Nottingham, Queen's Medical Centre, Nottingham, United Kingdom

In myotonic dystrophy, muscleblind-like protein 1 (MBNL1) protein binds specifically to expanded CUG or CCUG repeats, which accumulate as discrete nuclear foci, and this is thought to prevent its function in the regulation of alternative splicing of pre-mRNAs. There is strong evidence for the role of the MBNL1 gene in disease pathology, but the roles of two related genes, MBNL2 and MBNL3, are less clear. Using new monoclonal antibodies specific for each of the three gene products, we found that MBNL2 decreased during human fetal development and myoblast culture, while MBNL1 was unchanged. In Duchenne muscular dystrophy muscle, MBNL2 was elevated in immature, regenerating fibres compared with mature fibres, supporting some developmental role for MBNL2. MBNL3 was found only in C2C12 mouse myoblasts. Both MBNL1 and MBNL2 were partially sequestered by nuclear foci of expanded repeats in adult muscle and cultured cells from myotonic dystrophy patients. In adult muscle nucleoplasm, both proteins were reduced in myotonic dystrophy type 1 compared with an age-matched control. In normal human myoblast cultures, MBNL1 and MBNL2 always co-distributed but their distribution could change rapidly from nucleoplasmic to cytoplasmic. Functional differences between MBNL1 and MBNL2 have not yet been found and may prove quite sub- tle. The dominance of MBNL1 in mature, striated muscle would explain why ablation of the mouse mbnl1 gene alone is sufficient to cause a myotonic dystrophy. (Am J Pathol 2009, 174:216-227; DOI: 10.2353/ajpath.2009.080520)

Myotonic dystrophy type 1 (DM1) is a progressive multisystemic disorder showing considerable clinical variation between individuals. DM1 is characterized by skeletal muscle weakness, wasting and pain, as well as myotonia. ${ }^{1}$ Other symptoms may include cardiac arrhythmias, cataracts, insulin resistance, hypogonadism, neurological problems and premature male balding. ${ }^{1-4}$ The genetic mutation responsible for DM1 has been identified as the expansion of a CTG repeat in exon 15 in the $3^{\prime}$ untranslated region of the DM protein kinase (DMPK) gene on chromosome 19q13.3..$^{5-7}$ The largest germline expansions occur during maternal transmission but the length of repeats may also increase somatically in affected individuals. ${ }^{8}$ The size of the CTG expansion is related to the disease severity. More than 50 CTG repeats cause mild to classical adult-onset DM and 700 to greater than 3000 repeats often result in the severe congenital form of the disease. However, repeat size in muscle and other tissues can be much higher than in lymphocytes. ${ }^{9} \mathrm{~A}$ second form of DM (DM2) is due to a CCTG repeat in intron 1 of the ZNF9 gene on chromosome 3q21.3. ${ }^{10}$ Clinical features of DM1 and DM2 are similar but not identical. DM2 patients may show proximal rather than distal muscle involvement, and the severe congenital form occurs in DM1 only. The number of repeats in DM2 may be 10 -fold greater than in DM1. ${ }^{10}$

Supported by funding from the Muscular Dystrophy Campaign (RA3/663), Association Française contre les Myopathies, University Paris 6, INSERM and Myores $6^{\text {th }}$ Framework European Network.

Accepted for publication September 12, 2008.

Address reprint requests to Prof. G. E. Morris at Wolfson Centre for Inherited Neuromuscular Disease, RJAH Orthopaedic Hospital, Oswestry, Shropshire, SY10 7AG, UK. E-mail: glenn.morris@rjah.nhs.uk. 
Current evidence suggests that DM pathogenesis is due to the toxic gain of function of the mutant RNA. Transgenic mouse models with expanded CUG repeats in the $3^{\prime}$-UTR of the unrelated muscle-specific actin or the human DMPK transcripts develop features of DM1, ${ }^{11,12}$ suggesting that the major clinical features of DM1 are due directly to the repeat expansion. The expanded repeats in DM1 and DM2 accumulate in the nuclei as discrete foci. ${ }^{13-16}$ The relationship between these ribonuclear inclusions, which may consist of double stranded hairpin loop structures, ${ }^{17,18}$ and DM pathogenesis is not entirely clear. ${ }^{19}$ Mutant DMPK mRNA in nuclear foci of DM1 cells appears to be spliced and polyadenylated normally, ${ }^{15}$ whereas DM2 foci appear to consist of spliced-out introns. ${ }^{16}$ As a result of this difference, DM1 foci accumulate at the periphery of nuclear splicing "speckles" on the mRNA export pathway, whereas DM2 foci do not. ${ }^{20}$

The Drosophila muscleblind protein, first described as a regulatory factor required for the differentiation of photoreceptor cells and muscle Z-bands, ${ }^{21,22}$ is an RNA binding protein. There are three human homologues of the muscleblind gene, MBNL1, MBNL2, and MBNL3 on chromosomes 3q25, 13q32.2 and Xq26.2 respectively, with different RNA splice forms occurring. ${ }^{23}$ Muscleblind proteins have been shown to bind specifically to expanded dsCUG RNA but not normal size CUG repeats, in a manner proportional to the size of the triplet repeat expansion. ${ }^{24}$ Transfected MBNL1, MBNL2, and MBNL3 colocalize with the expanded CUG/CCUG ribonuclear inclusions in DM cells. ${ }^{19,23,25,26}$ Several studies have reported the colocalization of endogenous MBNL1 with ribonuclear foci, ${ }^{19,20,24,27-31}$ and one study suggests that MBNL1 is required for focus formation..$^{32}$ In addition, a mouse functional knockout of MBNL1 shows DM features, such as myotonia, abnormal myofibers, cataracts and aberrant splicing of chloride channel, cardiac tropo$\operatorname{nin} \mathrm{T}$, and fast skeletal troponin $\mathrm{T}^{33}$

At least some of the pathological features of DM are thought to be due to misregulated alternative splicing of RNA. Misregulated alternative splicing in DM has been reported for at least 20 gene transcripts (cited by Osborne and Thornton, ${ }^{34}$ ), including the muscle-specific chloride channel, insulin receptor, brain microtubule-associated tau, MBNL1 and MBNL2. MBNL proteins have been shown to bind specific targets on cardiac troponin T pre-mRNA (from the TNNT2 gene) and to regulate alternative splicing by repressing exon inclusion in TNNT2 mRNA and inducing exon inclusion in insulin receptor mRNA. ${ }^{35}$ Recently, overexpression of MBNL1 in a poly(CUG) mouse model for DM has been shown to reverse myotonia and correct the mis-splicing of four pre-mRNAs. ${ }^{36}$ Sequestration of MBNL1 by CUG repeats is therefore strongly implicated in the pathogenesis of $\mathrm{DM},{ }^{34}$ but there is also evidence that elevation of CUGBP1 may also play a role. ${ }^{37,38}$ Endogenous MBNL2 has been little studied, but it does colocalize with ribonuclear foci in sections of cortical neurons ${ }^{29}$ and heart ${ }^{30}$ from DM1 patients and is able to regulate alternative splicing. ${ }^{35}$ MBNL2 has also been reported to colocalize with integrin alpha3 mRNA at integrin-containing adhesion plaques, and it was suggested that MBNL2 may transport integrin alpha3 mRNA from the nucleus to the cytoplasm, ${ }^{39}$ but the question of whether MBNL1 has a similar role was not examined. MBNL3 mRNA was present in placenta but was absent from all other tissue tested including skeletal muscle and heart. ${ }^{23}$ MBNL3 has been shown to inhibit markers of muscle differentiation in mouse myoblast cultures..$^{40}$

Faustino and $\mathrm{Cooper}^{37}$ have reviewed the arguments in favor of a contribution of CUG-BP upregulation to missplicing in DM1. CUG-BP is not elevated in DM2 muscle biopsies or in muscle from the DM mouse model expressing 250 CUG repeats in the $3^{\prime}$-UTR of the skeletal muscle actin mRNA. ${ }^{31} \mathrm{~A}$ recent mouse model with 960 repeats in DMPK exon 15 did show CUG-BP upregulation with associated splicing changes, ${ }^{38}$ although the 960 repeats were multiple interrupted concatamers rather than typical DM1 repeats. Large CUG and CAG transfected 960repeats form nuclear foci that bind MBNL1, but only CUG repeats caused the RNA splicing changes associated with DM1, suggesting that MBNL sequestration alone is insufficient to alter splicing. ${ }^{19}$ In contrast, Miller et $\mathrm{al}^{24}$ found that $(\mathrm{CAG})_{54}$ bound very little MBNL1 in vitro, compared with $(C \cup G)_{54}$, but in neither study is the CUG repeat sequence typical of DM1. On the relationship between nuclear foci, clinical severity and repeat size, two individuals with around 60 CUG repeats had no foci and no clinical signs of muscle disease, whereas two DM1 patients with around 75 repeats had "infrequent" foci and mild, late-onset muscle weakness. ${ }^{27}$ However, with repeat sizes $>100$, no correlation with the number or size of nuclear foci was observed. ${ }^{27}$

Ebralidze et al ${ }^{41}$ suggested an alternative or additional mechanism, showing that expanded CUG repeats sequester transcription factors, such as Sp1, STAT1, STAT3, and RAR-gamma, from chromatin and that this can result in a decreased level of the muscle chloride channel, which is reversible by overexpression of Sp1.

In the present study, we have developed and characterized new monoclonal antibodies against the three human MBNL proteins. We have shown that MBNL2 decreases during myoblast differentiation and human muscle development, leaving MBNL1 as the major isoform in mature muscle.

\section{Materials and Methods}

\section{Antibody Production}

Human MBNL1 cDNA was amplified from pEGFP/ MBNL1 ${ }^{25}$ using primers 5'-GCGGATCCCGTCACACCAATTCGGGA-3' and 5'-GCGTCGACGTCAGATGTTCGGCAGATATTATGG-3' with BamHI and Sall sites (underlined) for cloning into pET21b (as described previously ${ }^{20}$ ). The amplified sequence of MBNL1 for recombinant protein production contained exons $1,2,3,4$, and 6 of MBNL1 variant 1 (Accession NM021038) (exon numbering from Pascual et $\mathrm{al}^{4}{ }^{42}$ ). MBNL2 cDNA was amplified from pEGFP/MBNL2 ${ }^{23}$ using primers 5'-GCGAATTCCATGGCTTTGAACGTTGC-3' and 5'-GCGTCGACGATCCGGTGGATCCGC-3' with EcoRI 
and Sall sites (underlined) for cloning into pET21b. (Note: the reverse primer codes for part of the pEGFP plasmid sequence). This CDNA is MBNL2 variant 2 (Accession AF061261) containing exons 1, 2, 3 and part of exon 4 (exon numbering from Pascual et $\mathrm{al}^{4}{ }^{42}$ ). The MBNL2 cDNA used for recombinant protein production is present in all three of the MBNL2 variants described $\mathrm{in}^{42}$ ). MBNL3 cDNA was digested directly from pEGFP/MBNL $3^{24}$ using EcoRl and Sall and cloned into pET21b. This cDNA is MBNL3 variant 5 (AY372211). ${ }^{42}$ Therefore, this sequence will be present in MBNL3 variants 1, 5 and 6; but may not necessarily be present in MBNL3 variants 2, 3 and 4 .

After transformation of $E$. coli BL21(DE3) with the $\mathrm{pET}$ constructs and induction with IPTG, bacterial pellets were washed by sonication in TNE buffer and recombinant protein extracted by sonication in $6 \mathrm{~mol} / \mathrm{L}$ urea in PBS. MBNL1 and MBNL2 were purified by His-tag column chromatography in $6 \mathrm{~mol} / \mathrm{L}$ urea. The recombinant proteins were used as immunogens for production of monoclonal antibodies using the hybridoma method. ${ }^{43}$ Resulting hybridoma culture supernatants were screened initially by enzyme-linked immunosorbent assay and Western blot against the recombinant protein. Enzymelinked immunosorbent assay-positive supernatants were further screened by western blotting of human muscle extracts and for colocalization with transfected pEGFP/ MBNL1, 2 or 3 in COS-7 cells. Hybridomas were cloned twice by limiting dilution and Ig subclasses were determined using an isotyping kit (Zymed Labs Inc., San Francisco). Monoclonal antibody MB1a (20 and Results) recognizes the linker between two zinc finger domains (exon $3^{42}$ ) since it failed to bind recombinant MBNL1 lacking only this region (data not shown).

\section{SDS-Polyacrylamide Gel Electrophoresis and Western Blotting}

Cell and muscle samples were extracted in 1\% SDS buffer and boiled for 3 minutes. Proteins $(30 \mu \mathrm{g})$ were subjected to SDS-polyacrylamide gel electrophoresis (PAGE) using 10\% polyacrylamide gels and transferred to nitrocellulose membranes (BioRad). After blocking non-specific sites, membranes were incubated with primary antibodies: the monoclonal antibodies against MBNL were used at a dilution of $1 / 100$ of the culture supernatant and a monoclonal antibody against emerin was used as a loading control for cell culture extract. ${ }^{44}$ Antibody reacting bands were visualized following development with peroxidase-labeled goat anti-mouse $\mathrm{Ig}$ and a chemiluminescent detection system (SuperSignal, Pierce). The sum of the peak areas of major protein bands on a stain gel were used to estimate relative protein content of muscle extracts.

\section{Biopsies and Eukaryotic Cell Culture}

Biopsies for Western blot were obtained from quadriceps muscles during autopsies, in accordance with French legislation on ethical rules. Control biopsies (20 and 31 weeks) were from aborted fetuses and the adult muscle was from a 56-year-old male, all showing no sign of neuromuscular disease. Myoblasts were isolated from normal and DM1 fetal quadriceps muscles and established in culture as described previously. ${ }^{45}$ One DM1 myoblast cell line ("800 CTG") came from a subject with a CTG repeat size of 800 determined prenatally in trophoblasts, while another ("1300 CTG") had a CTG repeat size of 1300 determined prenatally in trophoblasts and 2300 determined in the myoblast cells. CTG repeat sizes are usually higher in muscle ${ }^{9}$ and may also vary during cell culture. Human myoblasts were grown in Dulbecco's Minimal Essential Medium (DMEM) (Gibco) supplemented with $20 \%$ decomplemented fetal bovine serum (FBS; Gibco) and antibiotics. To promote differentiation, growth medium was changed to skeletal muscle cell differentiation medium (PromoCell, Heidelberg). DM1 and DM2 fibroblasts were established in culture from a skin biopsy, ${ }^{23}$ following appropriate local ethical regulations. The CTG repeat size was greater than 2000 for the DM1 fibroblast line, but not determined for the DM2 cells. Human fibroblasts and COS-7 (monkey kidney fibroblasts) were grown in DMEM with 20\% fetal bovine serum and antibiotics. All cultures were incubated at $37^{\circ} \mathrm{C}$ in a humid air atmosphere containing $5 \% \mathrm{CO}_{2}$. After the incubation period, cells on coverslips were either fixed with 50:50 acetone-methanol for 5 minutes, or with 1\% formalin in PBS followed sequentially by $1 \%$ Triton X-100 in PBS and $0.1 \mathrm{~mol} / \mathrm{L}$ glycine in PBS.

\section{Immunohistochemistry}

Cells on coverslips were washed four times with casein buffer $(0.1 \%$ casein in $154 \mathrm{mmol} / \mathrm{L} \mathrm{NaCl}, 10 \mathrm{mmol} / \mathrm{L}$ Tris, $\mathrm{pH}$ 7.6). Culture supernatants containing anti-MBNL monoclonal antibodies were diluted 1:3 in PBS and incubated on coverslips for 1 hour. Alternatively, to stain for creatine kinase (CK), cells were incubated with 1:3 monoclonal anti-CK JAC ${ }^{46}$ for 1 hour. Primary antibody was then removed by washing four times with casein buffer. Cells were then incubated with $5 \mu \mathrm{g} / \mathrm{ml}$ goat anti-mouse ALEXA 488 (Molecular Probes, Eugene, Oregon, USA) secondary antibody diluted in PBS containing $1 \%$ horse serum, $1 \%$ fetal bovine serum and $0.1 \%$ BSA, for 1 hour. Ethidium bromide or 4,6-diamidino-2-phenylindole (DAPI) was added for the final 5 minutes of incubation to counterstain nuclei before mounting in Hydromount (Merck).

To identify regenerating muscle fibers, unfixed cryostat sections $(5 \mu \mathrm{m})$ of skeletal muscle from a Duchenne muscular dystrophy patient were incubated with monoclonal anti-neonatal myosin antibody (Novocastra, NCL$\mathrm{MHCn}$ ). Serial sections that had been fixed with $1 \%$ formalin were incubated with monoclonal anti-MBNL2. Secondary antibody and ethidium bromide stain are described above. For densitometry measurements, $5 \mu \mathrm{m}$ skeletal muscle biopsies from a congenital DM1 patient and an aged matched control (diagnostic biopsy with a non-DM diagnosis) were fixed with formalin and incubated with monoclonal antibodies MB1a, MB2a, or MB3a, or with culture medium control. Secondary antibody and 
DAPI are described above. Research protocols were approved by the RJAH Orthopaedic Hospital Research Committee. Human tissue was obtained with appropriate informed consent and ethical approval.

\section{In Situ Hybridization}

Labeling of ribonuclear foci was based on the methods of Taneja et $\mathrm{al}^{13}$ and Fardaei et al. ${ }^{25}$ Cells on coverslips were fixed in $4 \%$ paraformaldehyde, $5 \mathrm{mmol} / \mathrm{L} \mathrm{MgCl}_{2}$ in PBS for 10 minutes and washed with $2 \times$ SSC (300 $\mathrm{mmol} / \mathrm{L}$ sodium chloride, $30 \mathrm{mmol} / \mathrm{L}$ sodium citrate $\mathrm{pH} 7$ ). Cells were treated with $40 \%$ deionized formamide in $2 x$ SSC for 5 minutes, which was removed before addition of the in situ hybridization mix. The in situ hybridization mixes were prepared in $10 \%$ dextran sulfate, $40 \%$ formamide in $2 \times$ SSC as follows: $0.2 \%$ bovine serum albumin, 0.1 $\mathrm{mg} / \mathrm{ml}$ herring sperm DNA, $0.1 \mathrm{mg} / \mathrm{ml}$ baker's yeast transfer RNA (Sigma), 4 mmol/L ribonucleoside vanadyl complexes (Sigma). The probes used were either: $200 \mathrm{nmol} / \mathrm{L}$ Cy3-labeled (CAG) 10 oligonucleotide (Qiagen Operon, Cologne, Germany) for DM1, or 200 nmol/L Cy3-labeled $(\mathrm{CAGG})_{10}$ oligonucleotide for DM2. $200 \mu \mathrm{l}$ in situ hybridization mix was added to each coverslip and placed in a humidified incubated at $37^{\circ} \mathrm{C}$ for 16 hours. Cells were then washed thoroughly in $2 \times$ SSC and mounted in $\mathrm{Hy}$ dromount. For combined immunofluorescence and in situ hybridization, all washing steps were done with $2 \times$ SSC and antibodies diluted in 2X SSC. Cells on coverslips were fixed in 50:50 acetone-methanol for 5 minutes and washed. Monoclonal antibody was diluted 1:3 in 2x SSC and placed on the coverslips for 1 hour at $37^{\circ} \mathrm{C}$. Following washing, $5 \mu \mathrm{g} / \mathrm{ml}$ goat anti-mouse ALEXA 488 (Molecular Probes, Eugene, Oregon) in 2X SSC was added for 1 hour at $37^{\circ} \mathrm{C}$. The labeled cells were then treated with $4 \%$ paraformaldehyde, $5 \mathrm{mmol} / \mathrm{L} \mathrm{MgCl}_{2}$ for 1 minute and $40 \%$ formamide for 1 minute before addition of the in situ hybridization mix, as described previously.

Cells were examined and sequential confocal scans performed with a Nikon Eclipse E600 epifluorescence microscope with a BioRad MicroRadiance 2000 confocal scanning system (Zeiss, Welwyn Garden City, UK) or a Leica TCS SP5 spectral confocal microscope (Leica Microsystems, Milton Keynes, UK). The imaging lasers used were a Blue Diode $405 \mathrm{~nm}$ laser for DAPI, an Argon $488 \mathrm{~nm}$ laser for ALEXA 488 and a Helium/Neon $543 \mathrm{~nm}$ laser for $\mathrm{Cy} 3$ and ethidium bromide. Analysis of confocal images was performed with ImageJ software $(\mathrm{NIH})$.

\section{Transfection of Small Interfering RNA}

The small interfering RNA (siRNA) duplexes were synthesized by Genecust Europe (Dudelange, Luxembourg). The following sequences against MBNL1 were used: (a) 5'-CACUGGAAGUAUGUAGAGA-3'32 and (b) 5'-CAGACAGACUUGAGGUAUG-3' ${ }^{35}$ An siRNA against GADPH was used as control. HeLa cells were transfected using a solution of siRNA (100 nmol/L) and Oligofectamine (Invitrogen) according to the manufacturer's instructions. Proteins were harvested 72 hours after transfection.

\section{Results}

\section{Endogenous MBNL1 and MBNL2 Both Associate with Ribonuclear Repeat Foci in DM1 and $D M 2$}

Eight monoclonal antibodies (two each against MBNL1 and MBNL3, plus four against MBNL2) were produced

Table 1. Characterization of Anti-MBNL Monoclonal Antibodies

\begin{tabular}{|c|c|c|c|c|c|c|c|c|c|}
\hline \multirow[b]{3}{*}{ mAb name } & \multirow{3}{*}{$\begin{array}{c}\text { Antigen, clone and } \\
\text { subclass }\end{array}$} & & & & \multicolumn{3}{|c|}{ Western blot } & \multicolumn{2}{|c|}{ Immunofluorescence } \\
\hline & & \multicolumn{3}{|c|}{ ELISA $\left(\mathrm{A}_{490}\right)$} & \multirow{2}{*}{$\begin{array}{c}\text { Transfected } \\
\text { myoblasts }\end{array}$} & \multirow[b]{2}{*}{ HeLa } & \multirow{2}{*}{$\begin{array}{c}\text { Fetal human } \\
\text { muscle }\end{array}$} & \multirow{2}{*}{$\begin{array}{c}\text { Transfected } \\
\text { myoblasts }\end{array}$} & \multirow[b]{2}{*}{ DM1 myo } \\
\hline & & MBNL1 & MBNL2 & MBNL3 & & & & & \\
\hline MB1a & $\begin{array}{l}\text { MBNL1 } \\
4 A 8 \\
\text { lgG1 }\end{array}$ & 2.9 & $<0.1$ & $<0.1$ & + & + & + & + & + \\
\hline MB1b & $\begin{array}{l}5 \mathrm{F9} \\
\operatorname{lgG} 1 \\
\text { MBNL2 }\end{array}$ & 2.4 & 2.4 & 2.8 & + & + & + & + & - \\
\hline MB2a & $\begin{array}{l}\text { 3B4 } \\
\lg 62 b\end{array}$ & 0.1 & 2.8 & $<0.1$ & + & + & + & + & + \\
\hline MB2b & $\begin{array}{l}\text { 6A10 } \\
\lg 2 \mathrm{~b}\end{array}$ & 0.1 & 2.8 & $<0.1$ & + & + & + & + & + \\
\hline MB2c & $\begin{array}{l}8 \mathrm{~B} 1 \\
\operatorname{lgG} 1\end{array}$ & 0.1 & 2.6 & 0.1 & + & + & + & + & - \\
\hline \multirow[t]{2}{*}{ MB2d } & 9F11 & & & & & & & & \\
\hline & $\begin{array}{l}\text { IgG1 } \\
\text { MBNL3 }\end{array}$ & 0.1 & 2.3 & $<0.1$ & - & - & - & + & + \\
\hline MB3a & $\begin{array}{l}5 A 11 \\
\lg G 1\end{array}$ & $<0.1$ & $<0.1$ & 1.8 & + & - & - & + & - \\
\hline MB3b & $\begin{array}{l}\text { 2F9 } \\
\operatorname{lgG} 2 \mathrm{~b}\end{array}$ & $<0.1$ & 0.9 & 1.9 & + & - & - & + & - \\
\hline
\end{tabular}

Hybridoma clones were initially screened by ELISA. Selected clones were subsequently screened by western blot (extracts of COS-7 transfected with appropriate muscleblind isoform, HeLa cell extract, and human muscle cell extract) and by immunofluorescence microscopy (COS-7 cells transfected with appropriate muscleblind isoform and staining of foci in human DM myoblasts). ELISA results are shown as $\mathrm{A}_{490}$ values. Western blot and immunofluorescence results are shown as + (positive) or - (negative). 


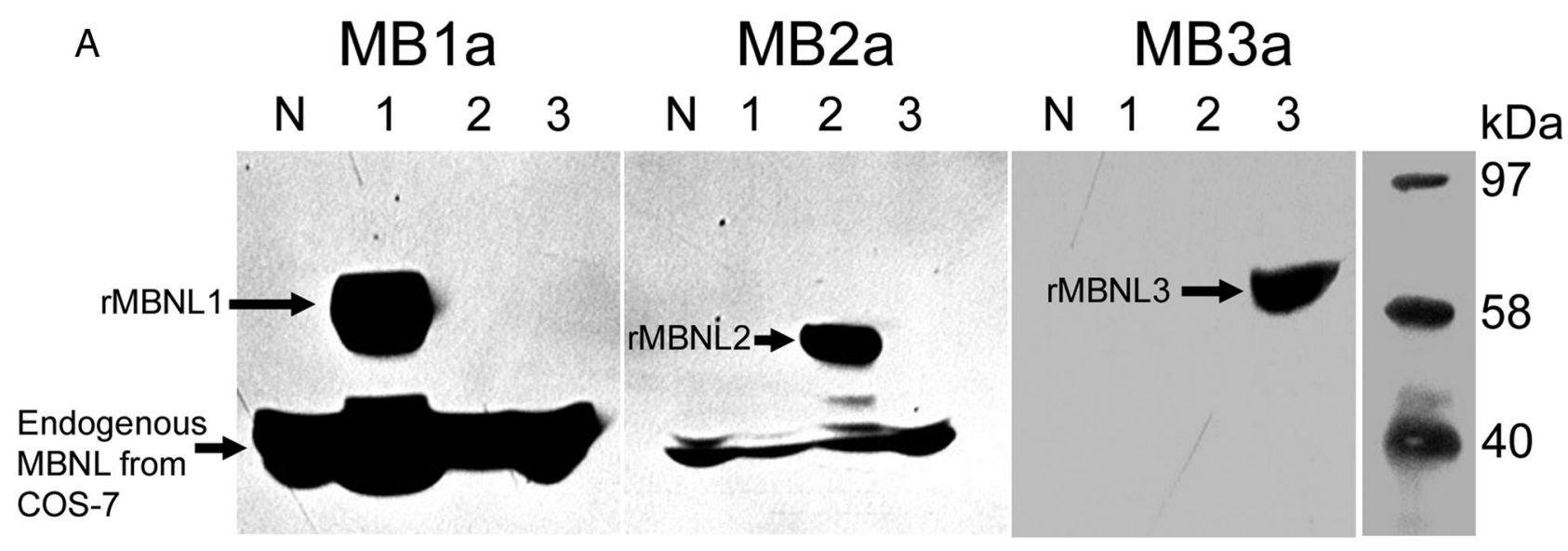

B

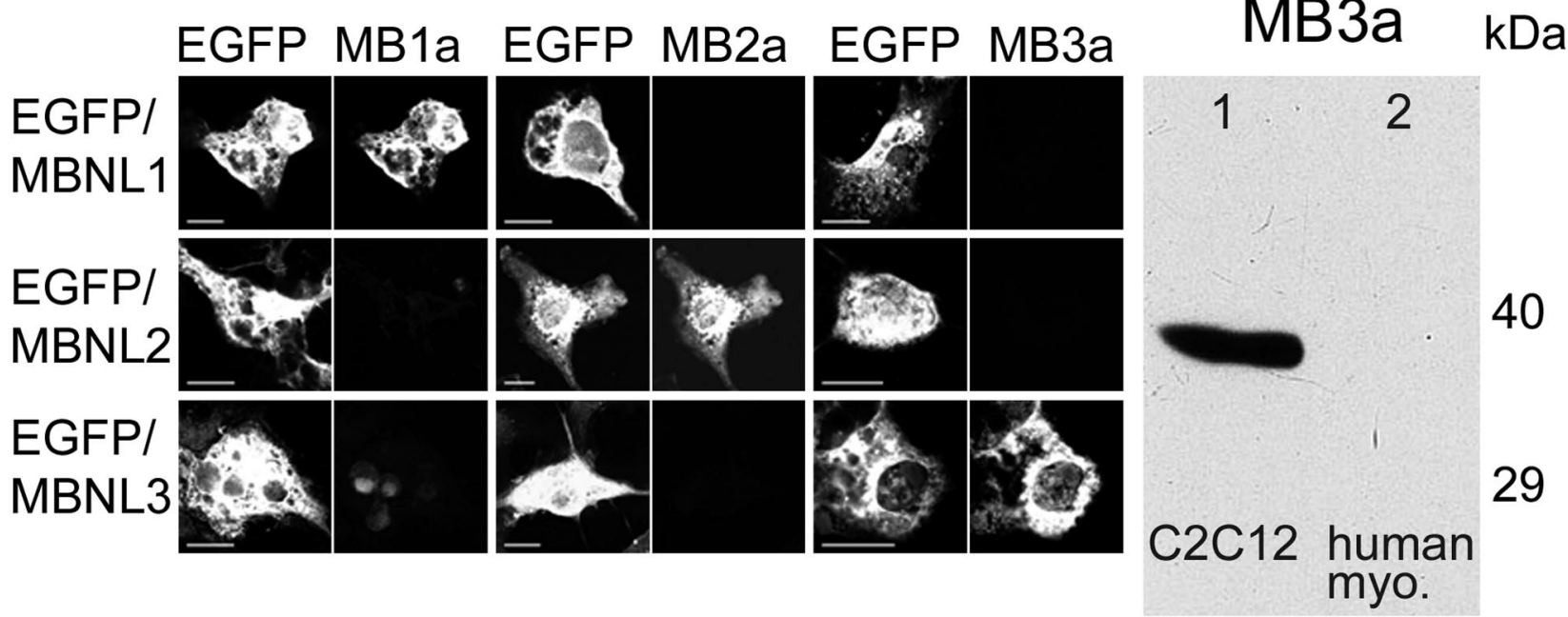

Figure 1. MBNL monoclonal antibodies are specific for each of the three isoforms in both Western blot and immunolocalization. A: COS-7 cells were transfected with EGFP constructs with MBNL1, MBNL2, or MBNL3 (1, 2, and 3) or left untransfected (N). The mAbs MB1a, MB2a, and MB3a detected their respective EGFP-fusion proteins on western blots, but did not cross-react with the other two fusion proteins. Endogenous monkey MBNL1 and MBNL2 have a lower Mr than the EGFP fusion proteins and were detected in all cell extracts. No endogenous MBNL3 was detected in COS-7 cells. B: COS-7 cells were transfected with EGFP constructs containing MBNL1, MBNL2, or MBNL3. Green fluorescence identified the transfected cells (left image of each pair). Each mAb showed intense staining of cells transfected with the corresponding MBNL isotype (right image of each pair) but did not cross-react with the other two isotypes. Some endogenous nuclear staining of COS-7 cells was seen with the MBNL1 mAb. Scale bar $=10 \mu \mathrm{m}$. C: Endogenous MBNL3 is detected in the mouse C2C12 myoblast cell line (lane 1), but not in human myoblast primary cultures (lane 2).

using the hybridoma method (Table 1) and their specificity for each protein was demonstrated by both western blotting of transfected enhanced green fluorescent fusion proteins at about $60 \mathrm{kD}$ (Figure 1A) and immunofluorescence microscopy (Figure 1B). One antibody against each protein was selected for subsequent studies, MB1a against MBNL1, MB2a against MBNL2, and MB3a against MBNL3. The availability of antibodies against two different epitopes for both MBNL1 and MBNL2 suggest that localizations reported here are authentic and not due to cross-reactions with other proteins. In the case of MBNL1, this was further confirmed using a polyclonal rabbit antiserum. Endogenous MBNL1 and, in smaller amounts, MBNL2 were detected at 40-42kDa in COS-7 cells (Figure 1A), but MBNL3 was only detected in mouse C2C12 myoblasts (Figure 1C), as reported previously. ${ }^{40}$ Further evidence for the specificity of the mAbs is the presence of only a single band or doublet on western blots of total HeLa cell extract (Figure 2A) or C2C12 extracts for MB3a (Figure 1C). The $\mathrm{mAb}, \mathrm{MB} 1 \mathrm{~b}$, reacts with both isoforms (Table 1) and recognizes both MBNL1 and MBNL2 bands (Figure 2A). Knockdown of MBNL1 in HeLa cells using 2 different siRNAs showed that both bands in the 40 to $42-k D$ doublet were authentic MBNL1 (Figure 2B).

In myoblasts from DM1 patients (Figure $3 A$ ) and in skin fibroblasts from both DM1 (not shown) and DM2 (Figure 3B) patients, expanded CUG or CCUG repeats could be identified in nuclear foci using in situ hybridization. Both MBNL1 and MBNL2 colocalized with these nuclear foci, but MBNL3 was not detected (Figure 3). The present results show that, with a suitable antibody, endogenous MBNL2 can easily be localized in cultured cells and that it had a similar distribution to MBNL1, although the fluorescent signal was weaker. 


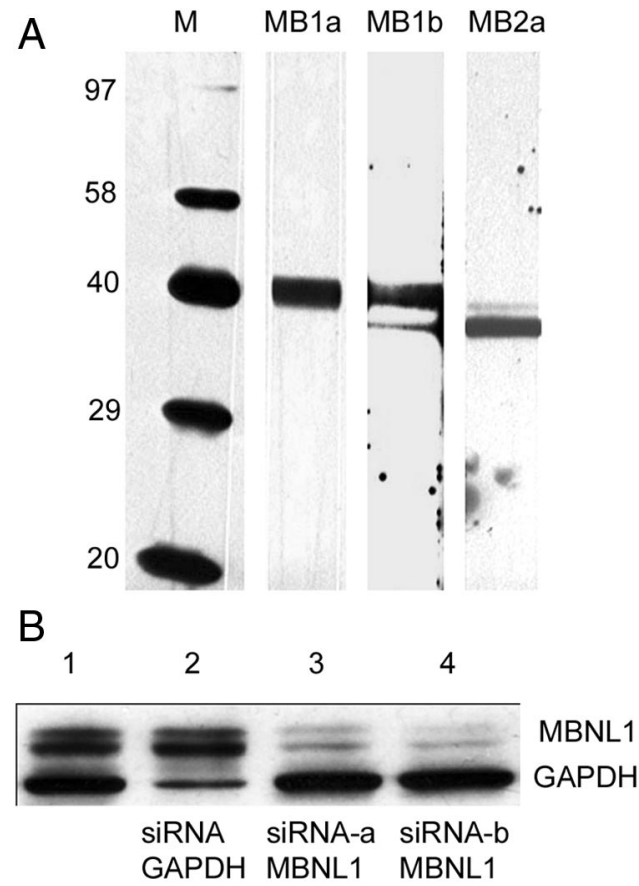

Figure 2. MBNL1 and MBNL2 antibodies do not cross-react with non-MBNL proteins on western blots of HeLa cells. A: MB1a mAb recognizes only MBNL1 (unresolved doublet at 40 to $42 \mathrm{kDa}$ ) and MB2a mAb recognizes only MBNL2. MB1b mAb recognizes both MBNL1 and MBNL2, but no non-MBNL proteins. Vertical strips of the same HeLa blot were developed with the three different antibodies for different exposure times. The intensities of the MBNL1 and MBNL2 bands stained by the same MB1b mAb may reflect the relative abundance of the two isoforms in HeLa cells. B: Two different siRNAs knocked down MBNL1 in HeLa cells without affecting the control protein glyceraldehyde-3-phosphate dehydrogenase $(38.4 \mathrm{kDa})$. This shows that both bands in the doublet are authentic MBNL1. Control glyceraldehyde-3phosphate dehydrogenase silencing did not affect MBNL1 levels.

\section{MBNL1 and MBNL2 Colocalize in Either the Nucleus or Cytoplasm of Differentiating Myoblasts, Depending on Culture Conditions}

In an earlier study, endogenous MBNL1 was mainly cytoplasmic in mouse C2C12 myoblasts but more evenly distributed in human myoblasts. ${ }^{24}$ When transfected as GFP-fusions, all three MBNL proteins were found in both nucleus and cytoplasm. ${ }^{23}$ We now show that the subcellular distribution of MBNL1 and MBNL2 can vary with myoblast cell culture conditions. Figure 4 shows that both MBNL1 and MBNL2 are mainly nucleoplasmic for at least 6 hours after normal human myoblasts adhere to coverslips, with clear absence of nucleolar staining. At 16-21 hours of culture, however, both proteins had become mainly cytoplasmic in this experiment, but by 24 hours their distribution was nucleoplasmic again and this persisted through the process of myoblast differentiation to form multinucleate myotubes. Similar relocation of MBNL1 and MBNL2 were seen when plating myoblasts on three separate occasions. Although the function of this redistribution is presently unclear, it is clearly a function shared by MBNL1 and MBNL2. In other experiments with the same cells, the cytoplasmic distribution persisted longer into the myotube stage (not shown), suggesting that the subcellular distribution of MBNL proteins is re-
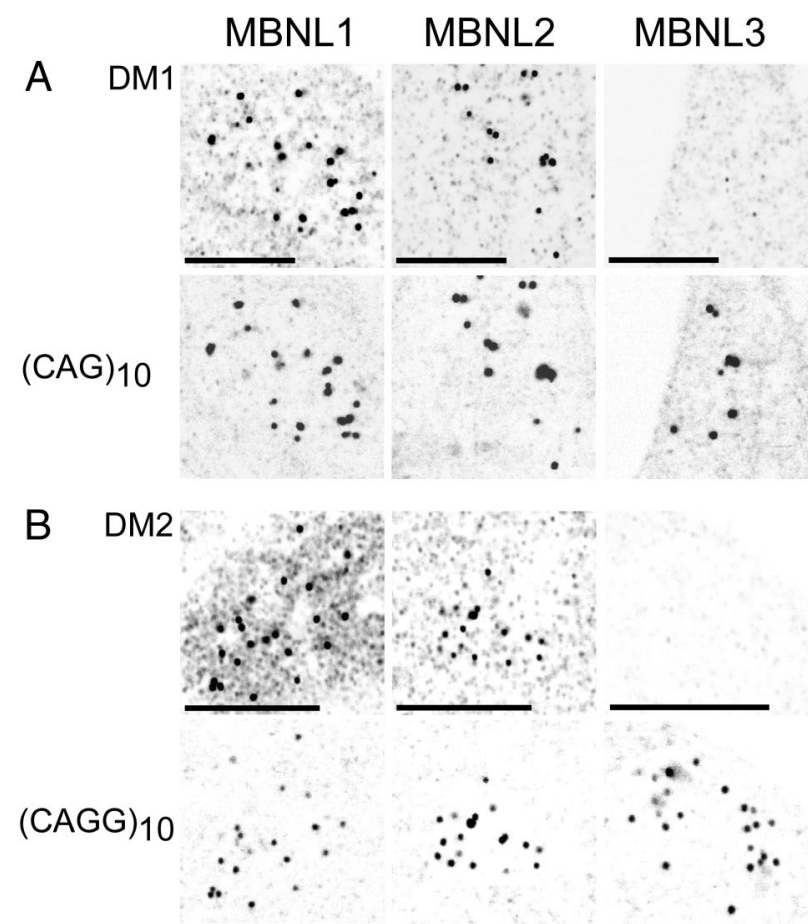

Figure 3. Colocalization of MBNL1 and MBNL2 with expanded RNA repeats in nuclear foci of DM1 and DM2 cultured cells. Immunolocalization (upper image of each pair; mAbs MB1a, MB2a, and MB3a) and in situ hybridization (lower image of each pair; $\mathbf{A}$ : $(\mathrm{CAG})_{10}$ probe and $\mathbf{B}$ : $(\mathrm{CAGG})_{10}$ probe) in $(\mathbf{A})$ DM1 myoblasts (800 CTG) and (B) DM2 skin fibroblasts (repeat size unknown). MBNL3 was not detected. Cells were fixed with acetone-methanol. Scale bar $=5 \mu \mathrm{m}$. Images are shown as inverted grayscale.

sponding to local signals or culture conditions, rather than any internal myogenic program.

\section{MBNL2 Levels Decrease during Muscle Development, but MBNL1 Remains Unchanged}

The levels of MBNL1 remained constant during the differentiation of both normal (Figure 5A) and DM1 (Figure $5 B$ ) myoblasts in culture. The levels of MBNL2 had clearly declined at day 3 , and they continued to decline to day 9 (Figure 5). The process of myoblast fusion to form myotubes and expression of muscle-specific proteins had begun by day 3 and continued through day 9 of culture. This observation was repeated in three independent experiments. Immunostaining for desmin showed that the human muscle cultures used in Figures 4 and 5 were $>90 \%$ myoblasts

Western blotting was also performed on extracts of human muscle at different stages of development (Figure $5 \mathrm{C})$. A decrease in MBNL2 was observed during development. In contrast, levels of MBNL1 in the same muscle extracts did not change significantly. Endogenous MBNL3 was not detected. The minor upper band of MBNL1 in human muscle may represent an alternatively spliced isoform. Kanadia et $\mathrm{al}^{36}$ observed MBNL1 bands at 40 and $41 \mathrm{kDa}$ in adult mouse muscle, and the upper band was also a minor component.

These results show that MBNL1 should have the dominant role in mature muscle and may partly explain why 

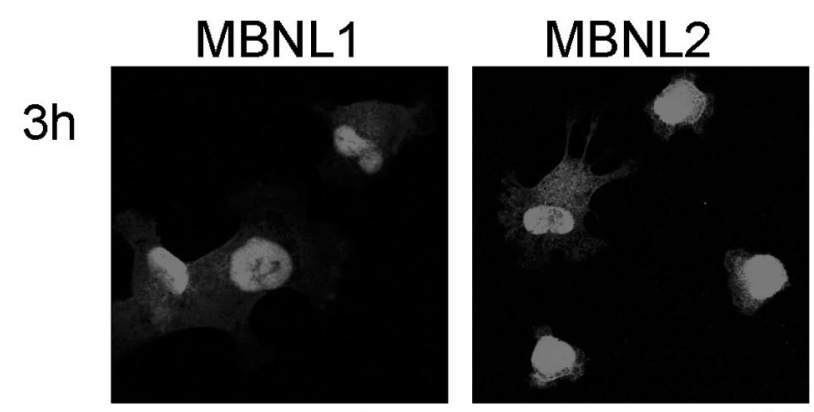

$6 \mathrm{~h}$
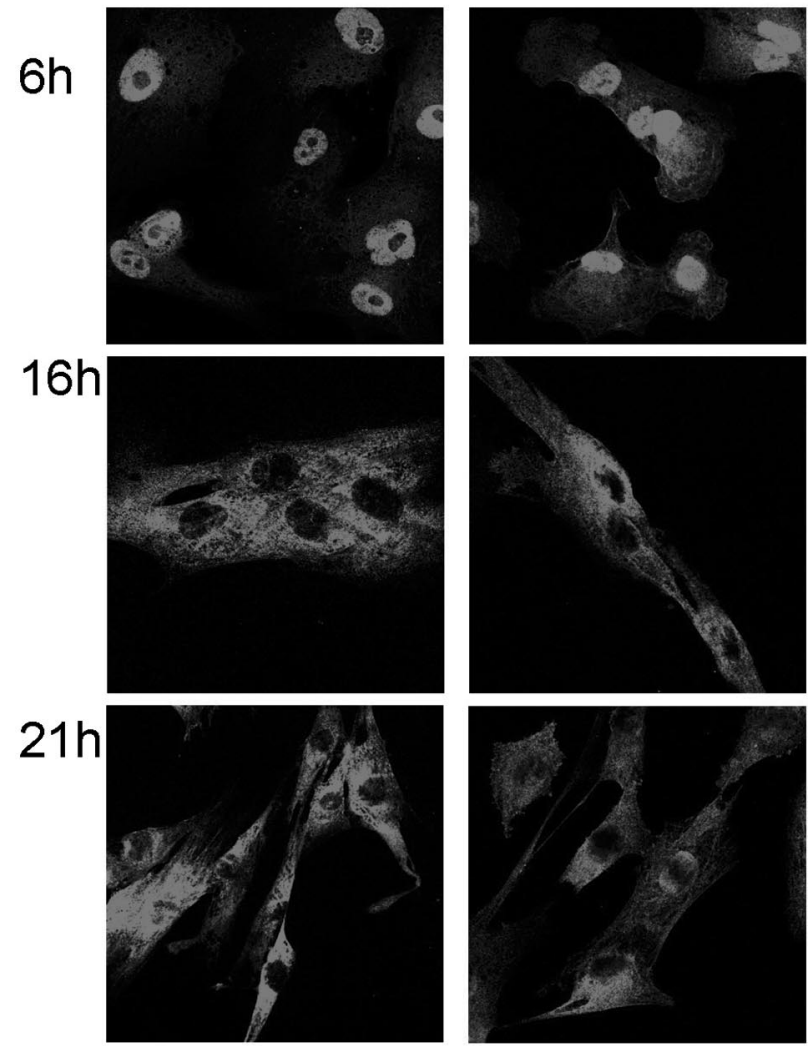

$1 d$
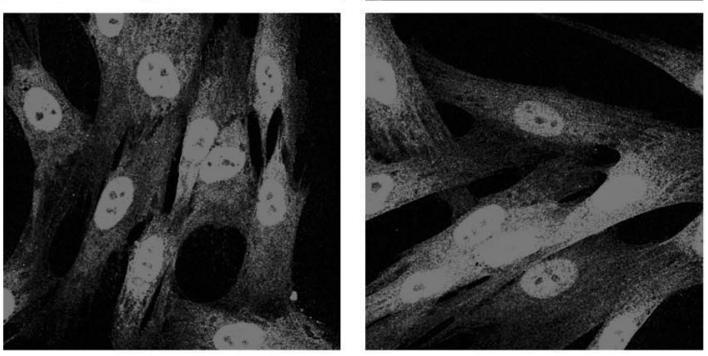

$4 d$
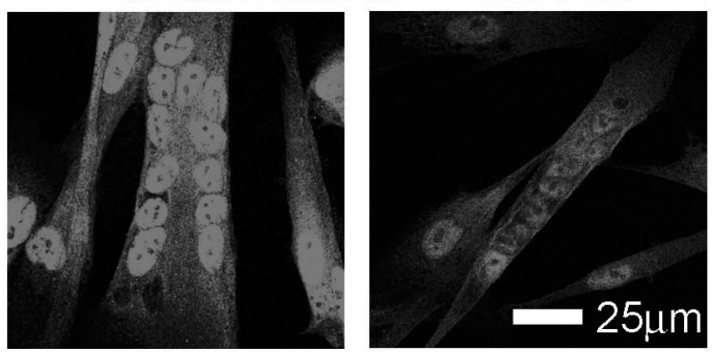

Figure 4. Changes in subcellular distribution of MBNL1 and MBNL2 during myoblast culture. Normal human myoblasts were grown on coverslips for various times before fixation with formalin, permeabilization with Triton X-100, and development with MB1a or MB2a mAbs, as described in the Methods. At day 1, the growth medium was changed to differentiation medium.
A normal myoblasts

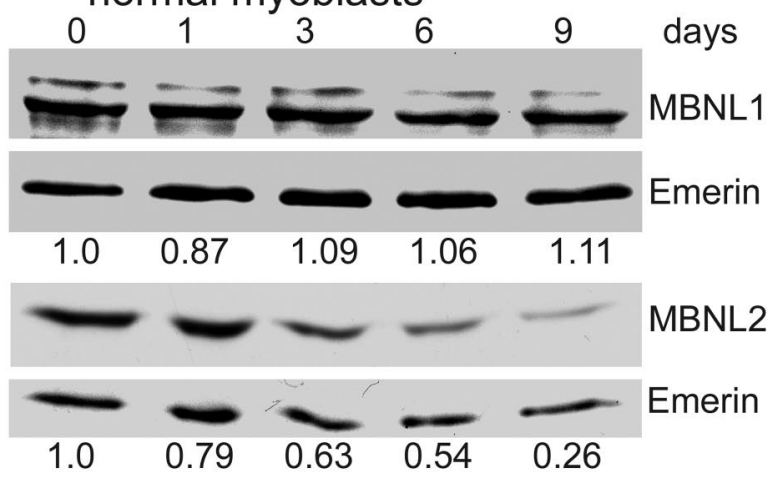

\section{B DM1 myoblasts}

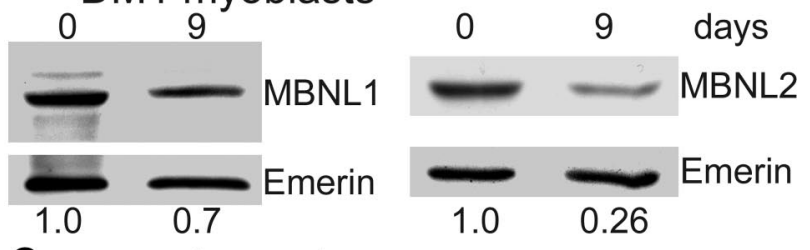

C normal muscle

MBNL1

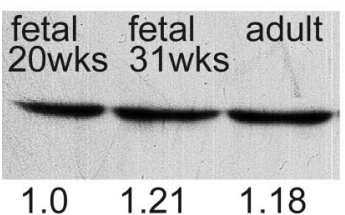

MBNL2

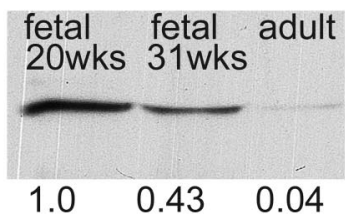

Figure 5. MBNL2 levels decrease during myogenesis in vitro and in vivo. $\mathbf{A}$, B: Western blots with mAbs against MBNL1 (MB1a), MBNL2 (MB2a), or emerin (MANEM5) with extracts of (A) control or (B) DM1 (1300 CTG) muscle cell cultures during differentiation (0 to 9 days). To control for loading variations, the intensity of MBNL1 or MBNL2 was expressed as a ratio of intensity of the corresponding band of emerin. Day 0 was assigned a value of 1.0. With values from two control and two DM1 experiments combined $(n=4)$, levels of MBNL1 were not significantly different between 0 and 9 days (ratio $=0.85 \pm 0.17 ; P=0.2$ ), whereas levels of MBNL2 decreased between these time points (ratio $=0.21 \pm 0.10 ; P<0.001$; Student's paired $t$-test). C: Western blots with MB1a and MB2a mAbs with extracts of control or DM1 muscle at different stages of development. Approximately equal amounts of total protein from each extract were loaded after determination of the peak areas of major protein bands on a stain gel.

MBNL2 cannot replace the functions of MBNL1 in MBNL1 knockout mouse muscle.

\section{MBNL2 Remains Elevated in Regenerating Muscle Fibers Expressing Neonatal Myosin}

Regenerating fibers in muscle biopsies from patients with neuromuscular disorders can be identified by their expression of neonatal myosin. Figure $6, \mathrm{~A}-\mathrm{C}$ shows a group of five such fibers identified in this way in a section of muscle from a patient with Duchenne muscular dystrophy. When this same area of muscle was immunostained for MBNL2 in a serial section (Figure 6, D-F), the nuclei of the regenerating fibers were clearly more strongly stained than the nuclei in surrounding mature fibers. Microdensitometry of nuclear MBNL2 staining gave values of $113 \pm 14$ for regenerating fibers compared with $56 \pm 13$ for mature fibers $(P<0.001$; Student's $t$-test). This is not due to redistribution of MBNL2 

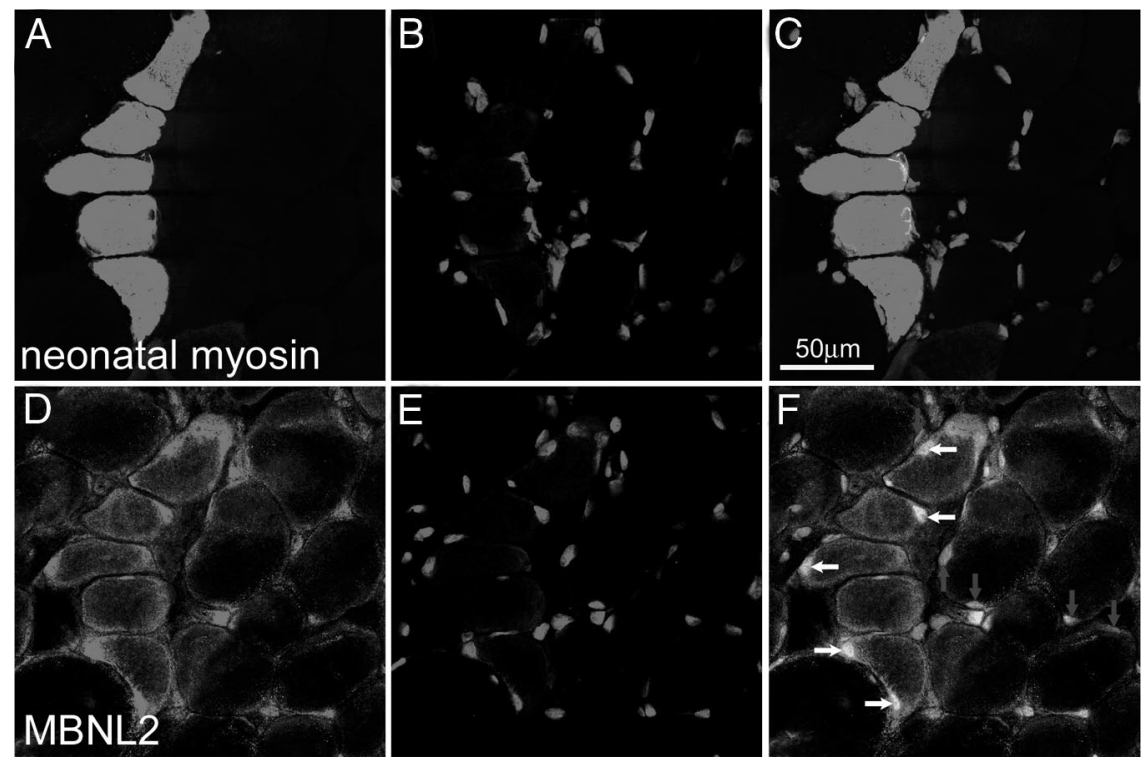

Figure 6. Higher levels of MBNL2 in regenerating muscle fibers in a skeletal muscle biopsy from a Duchenne muscular dystrophy patient Five regenerating fibers were identified by immunostaining with MHCn mAb (Novocastra, Newcastle, UK; 1:20) against neonatal myosin $(\mathbf{A}-\mathbf{C})$. In a serial section $(\mathbf{D}-\mathbf{F})$, nuclei in the regenerating fibers were more strongly stained for MBNL2 than nuclei in mature fibers (MB2a mAb; 1:4). The center panels show ethidium bromide staining of nuclei and the right panels are merged images. In (F), MBNL2 staining is indicated by horizontal white arrows in the nuclei of regenerating fibers and by vertical white arrows in the nuclei of mature fibers. from the cytoplasm to the nucleus because the cytoplasm of the regenerating fibers is also rather more strongly stained than surrounding fibers (Figure 6D). This shows that the down-regulation of MBNL2 during muscle development has not yet occurred in the immature regenerating fibers, which are derived from precursor satellite cells in the mature muscle tissue.

\section{MBNL1 and MBNL2 Are Partially Sequestered by Ribonuclear Foci}

DM pathogenesis is thought to involve the sequestration of MBNL1 into nuclear foci and loss of MBNL1 function in the nucleoplasm. This simple model appears to require a significant reduction in nucleoplasmic MBNL1 levels in DM nuclei. For reliable visualization of nuclear foci without high nucleoplasmic MBNL staining, we have used acetone:methanol fixation, which allows partial loss of "soluble" MBNL proteins from both cytoplasm and nucleoplasm (Figures 3 and 7), while the MBNL in nuclear foci remains attached to the nuclear matrix ${ }^{15}$ and/or splicing speckles. ${ }^{20}$ Cross-linking fixation with formalin prevents protein loss ${ }^{47}$ to give a more accurate view of authentic
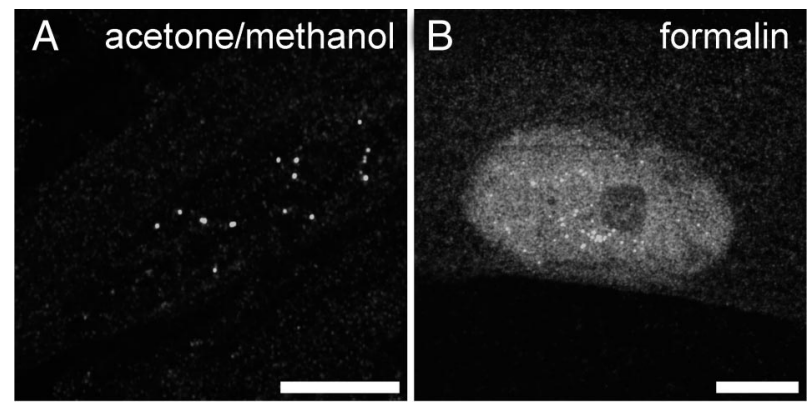

Figure 7. Fixation method affects visualization of MBNL1 in the nucleus. Cultured human DM1 myoblasts (800 CTG) were fixed and permeabilized either with acetone-methanol (A: two nuclei) or with formalin followed by Triton X-100 (B: one nucleus), as described in Materials and Methods. MBNL1 protein was detected using MB1a mAb. Scale bar $=10 \mu \mathrm{m}$.
MBNL distribution. With formalin fixation of DM1 myoblasts, nucleoplasmic MBNL1 staining was quite high, which sometimes obscured the foci (Figure 7). This nucleoplasmic staining is not due to smaller (31kD) splicing isoforms lacking the CUG repeat binding region, ${ }^{33}$ because our MBNL1 mAb does not recognize these smaller isoforms.

Sequestration of MBNL1 by expanded repeat foci is clearly incomplete in cultured myoblasts (Figure 7B), but it may be greater in adult muscle in vivo, where DMPK mRNA is expressed at higher levels. We therefore compared formalin-fixed muscle biopsy sections from a neonate with congenital DM1 and an age-matched control muscle biopsy. Figure 8 shows that nucleoplasmic MBNL1 and MBNL2 were still present in DM1 myonuclei with nuclear foci, although they both appear depleted visually. Microdensitometry of areas outside foci in Figure 8 confirmed reduced levels of both MBNL1 and MBNL2 in the DM1 nucleoplasm (Table 2). The intensity of nucleoplasmic staining was variable in both DM1 and control biopsies, but was always greater than the anti-MBNL3 (absent from muscle) background control. This extends earlier studies of MBNL1 depletion ${ }^{31}$ to show that MBNL2 is also depleted in DM1 nucleoplasm, though a wider study with more biopsies will be needed to quantify the effect more accurately.

Since DMPK levels increase during skeletal muscle development, ${ }^{45}$ one might expect the nuclear foci of DMPK mRNA to be larger or more numerous after myoblast differentiation. Using CK expression to identify differentiated cells (Figure 9), the average number of foci per nucleus in CK-positive cells was twice that of CKnegative cells (Table 3). Significantly, this was true both on day 0 and day 9 , confirming the link with muscle gene expression rather than cell density or time in culture. Davis et $\mathrm{al}^{15}$ showed an increase in both DMPK and numbers of foci after transfection of DM1 fibroblasts with MyoD and, in congenital DM1 myoblast cultures, foci 


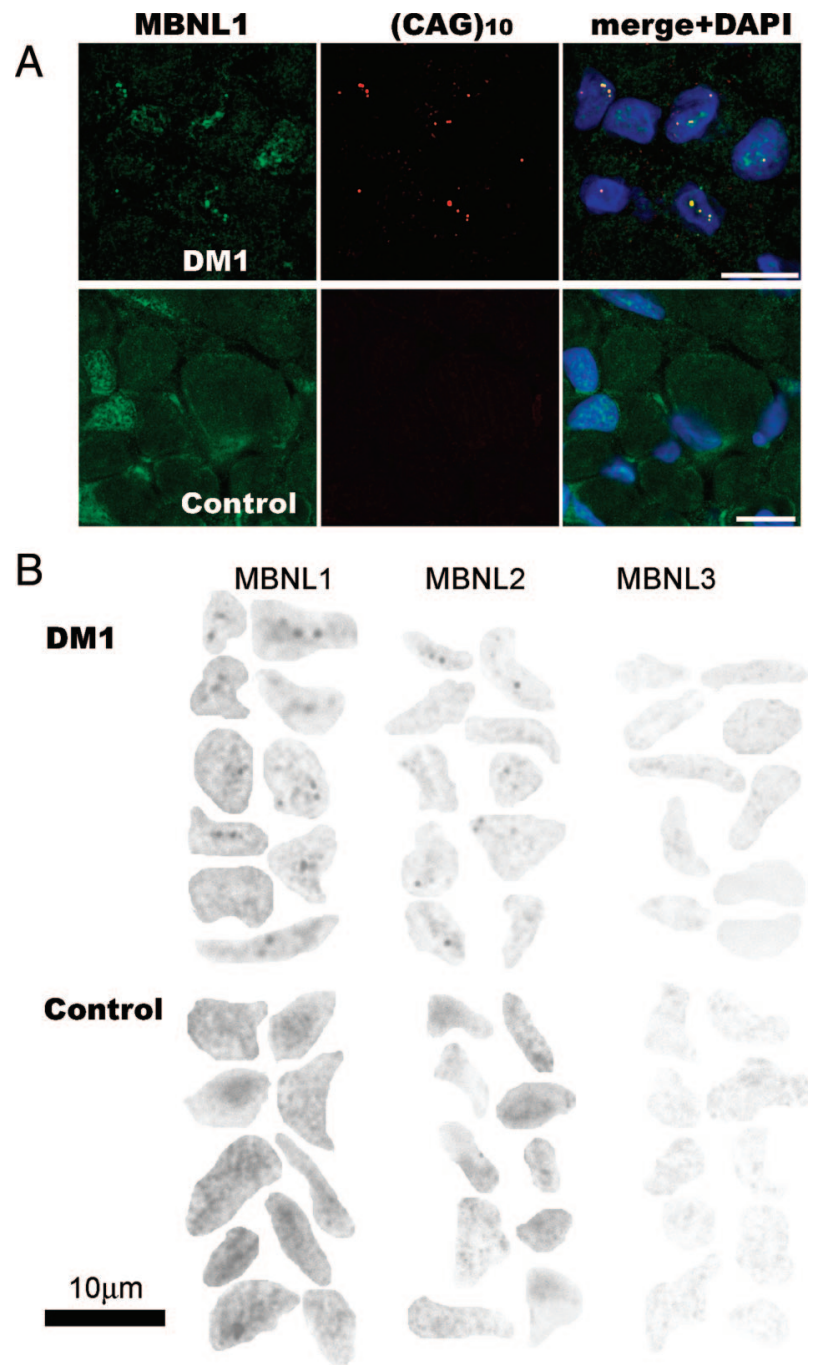

Figure 8. Nucleoplasmic levels of both MBNL1 and MBNL2 were lower in a muscle biopsy from a congenital DM1 patient (repeat size unknown) compared with an age-matched control biopsy (with a non-DM diagnosis) Frozen sections of DM1 and control skeletal muscle biopsies, were immunostained with MB1a, MB2a, MB3a, or control mAB. A: Nuclear foci were identified by in situ hybridization in the DM1 sections but not in the control. DM1 nuclear foci of mutant RNA are also intensely stained for MBNL1. Scale bar $=10 \mu \mathrm{m}$. B: Nucleoplasmic staining for MBNL1 and MBNL2 outside foci is visibly reduced, but not eliminated, in DM1 sections. The ten random nuclei shown were subjected to image analysis using ImageJ software (Table 2).

were brighter and more abundant in myotube nuclei compared with myoblast nuclei. ${ }^{45}$ Mankodi et al, ${ }^{28}$ however, reported a decrease in DM1 nuclear focus numbers during myogenesis in vitro.

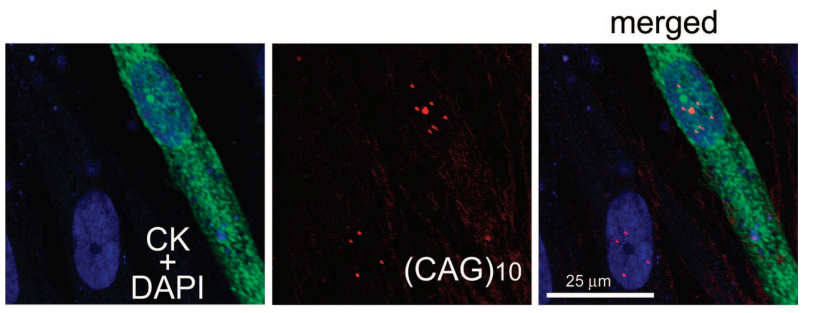

Figure 9. Differentiation of DM1 myoblasts (800 CTG) leads to a doubling in the number of foci per nucleus. Creatine kinase (CK) antibody ${ }^{46}$ was used to distinguish a CK-positive differentiated cell and a CK-negative myoblast in the same field (left, green). In situ hybridization was used to identify nuclear foci of mutant RNA in the same cells (center, red). Nuclei are counterstained with DAPI (blue). The CK-negative myoblast contains 4 foci and the CKpositive myoblast nucleus contains 7 to 10 foci.

\section{Discussion}

We have found that MBNL2 levels decrease during muscle development in vivo and in vitro, while MBNL1 levels remain unchanged. Miller et $\mathrm{al}^{24}$ found that MBNL1 increased dramatically during $\mathrm{C} 2 \mathrm{C} 12$ mouse myoblast differentiation, in parallel with a myosin heavy chain myogenic marker, but this may be a property of mouse or C2C12 only since they did not see it in human myoblast cultures. The $\mathrm{C} 2 \mathrm{C} 12$ cell line also differs in expressing MBNL3, which we did not find in human myoblasts. Human MBNL1 is clearly not a muscle-specific protein since it is present in both fused and unfused cells in the same culture (Figure 4) and is also present in nuclear foci in DM skin fibroblasts (Figure 3; 20). The decrease in MBNL2 levels during muscle development in vivo is consistent with the higher MBNL2 levels in regenerating fibers, which also represents an early stage in muscle development. Regenerating fibers differ from surrounding mature fibers in their continued expression of fetal muscle isoforms. Lin et al ${ }^{31}$ observed a postnatal decline of MBNL1 in mouse muscle in vivo, but did not study either the prenatal period or MBNL2. Some caution is required in making correlations with specific events in muscle development. Thus, MBNL2 declines during muscle fiber or myotube formation in culture, but the decline in MBNL2 observed in vivo during fetal development occurs during the period of muscle maturation (20 to 31 weeks), after initial fiber formation and the activation of muscle-specific genes has occurred. ${ }^{48}$ This is the period during which expression of fetal/neonatal myosin also declines sharply, ${ }^{49}$ so it is consistent that muscle regeneration is associated with both maintenance of higher MBNL2 lev-

Table 2. MBNL1 and MBNL2 are Reduced but Still Present in the Nucleoplasm of DM1 Skeletal Muscle Sections

\begin{tabular}{|c|c|c|c|c|c|}
\hline & MBNL1 & MBNL2 & MBNL3 & $\begin{array}{l}\text { MBNL1 minus } \\
\text { MBNL3 (bgd) }\end{array}$ & $\begin{array}{l}\text { MBNL2 minus } \\
\text { MBNL3 (bgd) }\end{array}$ \\
\hline Control & $60.8 \pm 13.6$ & $41.2 \pm 11.9$ & $14.2 \pm 3.9$ & 46.6 & 27.0 \\
\hline DM1 & $40.7 \pm 8.8^{*}$ & $24.9 \pm 2.4^{*}$ & $17.9 \pm 4.2^{* *}$ & $22.8(49 \%)$ & $7.0(26 \%)$ \\
\hline
\end{tabular}

Frozen sections $(5 \mu \mathrm{m})$ of skeletal muscle biopsies from a congenital DM1 patient and an age-matched control with a non-DM diagnosis, were immunostained with MB1a, MB2a, or MB3a mAbs and confocal images were collected under identical conditions. Nuclei were identified by DAPI staining, and their MBNL-stained images were converted to inverted gray scale (Figure 8B). ImageJ software was used to determine the mean gray values, outside nuclear foci, of ten nuclei in Fig.8. Results are shown as mean gray values \pm SD. $P$ values obtained by Student's $t$-test are comparisons of control and DM1 nuclei. There was no significant difference between culture medium control and MBNL3 in either control or DM1 nuclei ( $P>0.05$; not shown), so MBNL3 was used as a background control. The last two columns show MBNL1 and MBNL2 values minus the MBNL3 background (bgd). The values for DM1 as a percentage of the control are shown in brackets. ${ }^{\star} P<0.001,{ }^{\star *} P<0.05$. 
Table 3. The Mean Number of Nuclear Foci is Greater in DM1 Cells Expressing Muscle-Specific Proteins (Creatine Kinase)

\begin{tabular}{ccc}
\hline & \multicolumn{2}{c}{$\begin{array}{c}\text { Mean number of foci per } \\
\text { nucleus }( \pm \text { SD })\end{array}$} \\
\cline { 2 - 3 } Differentiation (days) & CK positive & CK negative \\
\hline $0(n=100)$ & $9.5( \pm 4.2)$ & $4.7( \pm 2.1)$ \\
$9(n=100)$ & $10.7( \pm 3.6)$ & $5.6( \pm 1.9)$ \\
\hline
\end{tabular}

Nuclear foci in DM1 myoblast cultures were labeled by in situ hybridization, and creatine kinase (CK) was labeled with CK-JAC mAb [46]. Significantly fewer foci per nucleus were present in CK-negative compared with CK-positive cells $(P<0.001$ at both timepoints; Student's $t$-test)

els and continued expression of the fetal/neonatal myosin isoform (Figure 6). However, this maturation from embryonic and fetal myosin isoforms to fast and slow muscle isoforms, characteristic of adult muscle, does not occur during myogenesis in vitro. Diversity of MBNL proteins is further increased by alternative splicing, MBNL1 having seven splice variants and MBNL2 having three. ${ }^{42}$ Our mAb MB2a against MBNL2 recognizes all three variants since the immunogen used was a shared N-terminal sequence. This observation rules out the possibility that the developmental changes in MBNL2 protein levels in Figures 4-6 were due to splice variant switching.

Transfection with recombinant MBNL proteins has previously shown that all three $M B N L$ gene products can bind to nuclear foci of expanded repeats, ${ }^{19,23,25,26}$ and we have shown that endogenous MBNL2, like MBNL1, is sequestered by nuclear foci in adult DM1 muscle and in cultured myoblasts and fibroblasts from both DM1 and DM2 patients. These data are important in view of the continuing search for functional differences between MBNL1 and MBNL2. Labeling of nuclear CUG-repeat foci by antibodies against MBNL was originally demonstrated using a polyclonal antiserum and a mAb, 3B10, both of which recognized all three muscleblind family members. ${ }^{24}$ Later, a specific mAb, 3A4, was used to confirm MBNL1 colocalization with nuclear foci in DM1 and DM2 muscle and cultured cells. ${ }^{27,28}$ A different mAb, 2D9, has recently been used to localize MBNL2 in nuclear foci in brain $^{29}$ and heart ${ }^{30}$ tissues from DM1 patients. Although cell lines expressing recombinant MBNL3 have been produced, ${ }^{40}$ neither we, nor others, have yet been able to detect endogenous MBNL3 in cultured human cells, possibly because the mRNA for MBNL3 is mainly expressed in placenta. ${ }^{23}$ The two mAbs, MB1a and MB2a, appear to have similar avidities for antigen, judging by their equally strong binding to recombinant proteins (Figure 1); this suggests that the weaker staining of MBNL2, compared with MBNL1 (Figure 5), is due to lower expression levels of MBNL2, especially in skeletal muscle. Consistent with this, microarray studies of adult human muscle found that MNBL2 mRNA levels were 10-fold, and MBNL3 100-fold, lower than MBNL1 mRNA levels. ${ }^{28}$

Lin et $\mathrm{al}^{31}$ found that nucleoplasmic MBNL1 was reduced by at least $78 \%$ in human DM1 muscle sections, using an antibody against a C-terminal MBNL1 peptide and a careful method designed to ensure that this difference was not due to selection of optical sections. In DM1 neuronal cell nucleoplasm, the reduction in MBNL1 immunostaining was $57 \%$, suggesting only partial sequestration by the nuclear foci. ${ }^{50}$ In the present study, using a similar method, we observed reduced levels in DM1 nucleoplasm of $51 \%$ and $74 \%$ for MBNL1 and MBNL2 (Figure 8). The anti-MBNL1 mAb used in this study, MB1a, recognizes the linker between the two zinc finger domains (the same epitope region as $\mathrm{mAb}, 3 \mathrm{~A} 4^{28}$ ), since it failed to bind to a recombinant MBNL1 lacking only this region (data not shown). MB1a recognizes the larger variants around 40 to $42 \mathrm{kDa}$ but not MBNL1 variants 4 and 5 around $35 \mathrm{kDa}$. In variants lacking this linker, the zinc finger domains cannot interact with expanded CUG repeats. ${ }^{18}$ Our localization studies for MBNL1, therefore, detect only those functional variants that are capable of sequestration by foci. All studies agree that nucleoplasmic MBNL1 is only partially sequestered into the large nuclear expanded repeat foci, but the existence of less aggregated CUG repeats that still interfere with MBNL1 function remains a possibility. Consequently, the continued presence of MBNL1 immunostaining in DM nucleoplasm does not rule out the sequestration hypothesis for DM pathogenesis.

The striking redistribution of MBNL protein from cytoplasm to nucleus during DM1 myoblast cell culture (Figure 4) occurs with both MBNL1 and MBNL2 but is not restricted to differentiated muscle cells (ie, cells expressing muscle-specific creatine kinase). An earlier study noted that MBNL1 was present in both cytoplasm and nucleus in normal human myoblasts, whereas it was mostly cytoplasmic in mouse $\mathrm{C} 2 \mathrm{C} 12$ myotubes. ${ }^{24} \mathrm{~A}$ recent study on neonatal mouse development observed a postnatal redistribution of MBNL1 from mainly sarcoplasmic to mainly nucleoplasmic between P2 and P20 in both normal mice and a DM1 transgenic model. ${ }^{31}$ The balance between nuclear and cytoplasmic MBNL proteins, and how this balance is regulated, is clearly important if myotonic dystrophy is caused by sequestration of nuclear MBNL1 into foci. ${ }^{20}$ What prevents nuclear uptake of cytoplasmic MBNL1 to replace that sequestered into foci? The C-terminal region of Drosophila muscleblind is required for nuclear localization since splicing isoform $A$ is predominantly cytoplasmic, while longer splice forms B and $C$ are nuclear. ${ }^{51}$ Removal of an exon 7-encoded sequence from mouse MBNL1 reduced its nuclear localization, and exon 7 exclusion increased postnatally in mice alongside nuclear localization. ${ }^{31}$ (Note that exon 7 described by Lin et $\mathrm{al}^{31}$ is equivalent to exon 5 described by Pascual et $\mathrm{al}^{42}$ ). However, the redistribution in Figure 4 may be too rapid to explain by isoform turnover and replacement.

Although the existence of three genes for MBNL presumably implies some differences in function between the three proteins, functional differences have not yet been clearly demonstrated. An unexpected function for MBNL2 in cytoplasmic mRNA transport has been reported, ${ }^{39}$ but it is not yet known whether MBNL 1 can also perform this function. In embryonic chick retina development, MBNL1 and MBNL2 become distributed in different regions of the photoreceptor, ${ }^{52}$ but it is not known whether they perform similar or different functions there. 
The MBNL1-deficient mouse has a DM-like phenotype, ${ }^{33}$ so the continued presence of MBNL2 evidently does not compensate for MBNL1 depletion, but this may be because MBNL2 levels are too low to do this in skeletal muscle after the developmental decline (Figure 5). When MBNL1 is more abundant, MBNL2 deficiency might affect only MBNL2-specific functions without affecting common functions. Lin et $\mathrm{al}^{31}$ found that a mouse with $>90 \%$ reduction in MBNL2 had no effect on muscle histology, myotonia or splicing of three RNAs that are affected by mbnl1 knockout (Serca1, ZASP and titin); however, this study was done in adult muscle, which may contain relatively little MBNL2 compared with MBNL1. More recently, Hao et $a^{53}$ described a different mbn/2 knockout mouse that did display myotonia and chloride channel mRNA splicing defects, though much less severe than the $m b n / 1$ knockout. This appears to suggest that MBNL1 and MBNL2 proteins have similar functions, but is difficult to reconcile with the lack of DM phenotype in heterozygotes of the MBNL1-deficient mice. ${ }^{33} \mathrm{Al}$ though a clear distinction between MBNL1 and MBNL2 functions has not yet been shown, our observation that MBNL2 specifically declines during muscle development, but remains high in regenerating muscle fibers, could reflect a role for MBNL2 in relation to specific RNAs involved in muscle development.

\section{Acknowledgments}

We thank Nicolas Sergeant, Claire-Marie Dhaenens, Suzanna Schraen, Valérie Vingtdeux and Nicolas Charlet (INSERM U837, Lille, France) for identifying the epitope recognized by MB1a, and Camille Lemercier and Virginie Francois for siRNA experiments.

\section{References}

1. Harper PS: Myotonic Dystrophy ed 3. WB Saunders, London, 2004

2. Ranum LP, Day JW: Myotonic dystrophy: rNA pathogenesis comes into focus. Am J Hum Genet 2004, 7:793-804

3. Day JW, Ranum LP: RNA pathogenesis of the myotonic dystrophies. Neuromuscul Disord 2005, 15:5-16

4. Machuca-Tzili L, Brook D, Hilton-Jones D: Clinical and molecular aspects of the myotonic dystrophies: a review. Muscle Nerve 2005, 32:1-18

5. Brook JD, McCurrach ME, Harley HG, Buckler AJ, Church D, Aburatani H, Hunter K, Stanton VP, Thirion JP, Hudson T, Sohn R, Zemelman B, Snell RG, Rundle SA, Crow S, Davies J, Shelbourne P, Buxton J, Jones C, Juvonen V, Johnson K, Harper PS, Shaw DJ, Housman DE: Molecular basis of myotonic dystrophy: expansion of a trinucleotide (CTG) repeat at the $3^{\prime}$ end of a transcript encoding a protein kinase family member. Cell 1992, 68:799-808

6. Fu YH, Pizzuti A, Fenwick RG, Jr., King J, Rajnarayan S, Dunne PW, Dubel J, Nasser GA, Ashizawa T, de Jong P, Wieringa B, Korneluk R, Perryman MB, Epstein HF, Caskey CT: An unstable triplet repeat in a gene related to myotonic muscular dystrophy. Science 1992, 255:1256-1258

7. Mahadevan M, Tsilfidis C, Sabourin L, Shutler G, Amemiya C, Jansen G, Neville C, Narang M, Barcelo J, O'Hoy K, Leblond S, EarleMacdonald J, de Jong PJ, Wieringa B, Korneluk RG: Myotonic dystrophy mutation: an unstable CTG repeat in the $3^{\prime}$ untranslated region of the gene. Science 1992, 255:1253-1255

8. Martorell L, Gámez J, Cayuela ML, Gould FK, McAbney JP, Ashizawa $\mathrm{T}$, Monckton DG, Baiget M: Germline mutational dynamics in myo- tonic dystrophy type 1 males: allele length and age effects. Neurology 2004, 62:269-274

9. Anvret M, Ahlberg G, Grandell U, Hedberg B, Johnson K, Edstrom L: Larger expansions of the CTG repeat in muscle compared to lymphocytes from patients with myotonic dystrophy. Hum Mol Genet 1993, 2:1397-1400

10. Liquori CL, Ricker K, Moseley ML, Jacobsen JF, Kress W, Naylor SL, Day JW, Ranum LP: Myotonic dystrophy type 2 caused by a CCTG expansion in intron 1 of ZNF9. Science 2001, 293:864-867

11. Mankodi A, Logigian E, Callahan L, McClain C, White R, Henderson D, Krym M, Thornton CA: Myotonic dystrophy in transgenic mice expressing an expanded CUG repeat. Science 2000, 289:1769-1773

12. Seznec H, Agbulut O, Sergeant N, Savouret C, Ghestem A, Tabti N, Willer JC, Ourth L, Duros C, Brisson E, Fouquet C, Butler-Browne G, Delacourte A, Junien C, Gourdon G: Mice transgenic for the human myotonic dystrophy region with expanded CTG repeats display muscular and brain abnormalities. Hum Mol Genet 2001, 10:2717-2726

13. Taneja KL, McCurrach M, Schalling M, Housman D, Singer RH: Foci of trinucleotide repeat transcripts in nuclei of myotonic dystrophy cells and tissues. J Cell Biol 1995, 128:995-1002

14. Hamshere MG, Newman EE, Alwazzan M, Athwal BS, Brook JD: Transcriptional abnormality in myotonic dystrophy affects DMPK but not neighboring genes. Proc Natl Acad Sci USA 1997, 94:7394-7399

15. Davis BM, McCurrach ME, Taneja KL, Singer RH, Housman DE: Expansion of a CUG trinucleotide repeat in the $3^{\prime}$ untranslated region of myotonic dystrophy protein kinase transcripts results in nuclear retention of transcripts. Proc Natl Acad Sci USA 1997, 94:7388-7393

16. Margolis JM, Schoser BG, Moseley ML, Day JW, Ranum LP: DM2 intronic expansions: evidence for CCUG accumulation without flanking sequence or effects on ZNF9 mRNA processing or protein expression. Hum Mol Genet 2006, 15:1808-1815

17. Jasinska A, Michlewski G, de Mezer M, Sobczak K, Kozlowski P. Napierala M, Krzyzosiak WJ: Structures of trinucleotide repeats in human transcripts and their functional implications. Nucleic Acids Res 2003, 31:5463-5468

18. Kino Y, Mori D, Oma Y, Takeshita Y, Sasagawa N, Ishiura S: Muscleblind protein. MBNL1/EXP, binds specifically to CHHG repeats. Hum Mol Genet 2004, 131:495-507

19. Ho TH, Savkur RS, Poulos MG, Mancini MA, Swanson MS, Cooper TA: Colocalization of muscleblind with RNA foci is separable from misregulation of alternative splicing in myotonic dystrophy. J Cell Sci 2005, 118:2923-2933

20. Holt I, Mittal S, Furling D, Butler-Browne GS, Brook JD, Morris GE: Defective mRNA in myotonic dystrophy accumulates at the periphery of nuclear splicing speckles. Genes Cells 2007, 12:1035-1048

21. Begemann G, Paricio N, Artero R, Kiss I, Perez-Alonso M, Mlodzik M: Muscleblind, a gene required for photoreceptor differentiation in Drosophila, encodes novel nuclear Cys3His-type zinc-finger-containing proteins. Development 1997, 12:4321-4331

22. Artero R, Prokop A, Paricio N, Begemann G, Pueyo I, Mlodzik M, Perez-Alonso M, Baylies MK: The muscleblind gene participates in the organization of Z-bands and epidermal attachments of Drosophila muscles and is regulated by Dmef2. Dev Biol 1998, 195:131-143

23. Fardaei M, Rogers MT, Thorpe HM, Larkin K, Hamshere MG, Harper PS, Brook JD: Three proteins. MBNL, MBLL and MBXL, co-localize in vivo with nuclear foci of expanded-repeat transcripts in DM1 and DM2 cells Hum Mol Genet 2002, 11:805-814

24. Miller JW, Urbinati CR, Teng-Umnuay P, Stenberg MG, Byrne BJ, Thornton CA, Swanson MS: Recruitment of human muscleblind proteins to (CUG) (n) expansions associated with myotonic dystrophy. EMBO J 2000, 19:4439-4448

25. Fardaei M, Larkin K, Brook JD, Hamshere MG: In vivo co-localisation of MBNL protein with DMPK expanded-repeat transcripts. Nucleic Acids Res 2001, 29:2766-2771

26. Paul S, Dansithong W, Kim D, Rossi J, Webster NJ, Comai L, Reddy $\mathrm{S}$ : Interaction of muscleblind. CUG-BP1 and hnRNP $\mathrm{H}$ proteins in DM1-associated aberrant IR splicing EMBO J 2006, 25:4271-4283

27. Mankodi A, Urbinati CR, Yuan QP, Moxley RT, Sansone V, Krym M, Henderson D, Schalling M, Swanson MS, Thornton CA: In vivo colocalisation of MBNL protein with DMPK expanded-repeat transcripts. Nucleic Acids Res 2001, 29:2766-2771

28. Mankodi A, Teng-Umnuay P, Krym M, Henderson D, Swanson M, Thornton CA: Ribonuclear inclusions in skeletal muscle in myotonic dystrophy types 1 and 2. Ann Neurol 2003, 54:760-768 
29. Jiang H, Mankodi A, Swanson MS, Moxley RT, Thornton CA: Muscleblind localizes to nuclear foci of aberrant RNA in myotonic dystrophy types 1 and 2. Hum Mol Genet 2001, 10:2165-2170

30. Mankodi A, Lin X, Blaxall BC, Swanson M, Thornton CA: Nuclear RNA foci in the heart in myotonic dystrophy. Circ Res 2005, 97:1152-1155

31. Lin X, Miller JW, Mankodi A, Swanson MS, Thornton CA: Failure of MBNL1-dependent post-natal splicing transitions in myotonic dystrophy. Hum Mol Genet 2006, 15:2087-2097

32. Dansithong W, Paul S, Comai L, Reddy S: MBNL1 is the primary determinant of focus formation and aberrant insulin receptor splicing in DM1. J Biol Chem 2005, 280:5773-5780

33. Kanadia RN, Johnstone KA, Mankodi A, Lungu C, Thornton CA, Esson D, Timmers AM, Hauswirth WW, Swanson MS: A muscleblind knockout model for myotonic dystrophy. Science 2003, 302:1978-1980

34. Osborne RJ, Thornton CA: RNA-dominant diseases. Hum Mol Genet 2006, 15:R162-169

35. Ho TH, Charlet-B N, Poulos MG, Singh G, Swanson MS, Cooper TA: Muscleblind proteins regulate alternative splicing. EMBO J 2004, 23:3103-3112

36. Kanadia RN, Shin J, Yuan Y, Beattie SG, Wheeler TM, Thornton CA, Swanson MS: Reversal of RNA missplicing and myotonia after muscleblind overexpression in a mouse poly(CUG) model for myotonic dystrophy. Proc Natl Acad Sci USA 2006, 103:11748-11753

37. Faustino NA, Cooper TA: Pre-mRNA splicing and human disease. Genes Dev 2003, 17:419-437

38. Orengo JP, Chambon P, Metzger D, Mosier DR, Snipes GJ, Cooper TA: Expanded CTG repeats within the DMPK 3' UTR causes severe skeletal muscle wasting in an inducible mouse model for myotonic dystrophy. Proc Natl Acad Sci USA 2008, 105:2646-2651

39. Adereth Y, Dammai V, Kose N, Li R, Hsu T: RNA-dependent integrin alpha3 protein localization regulated by the muscleblind-like protein MLP1. Nat Cell Biol 2005, 7:1240-1247

40. Squillace RM, Chenault DM, Wang EH: Inhibition of muscle differentiation by the novel muscleblind-related protein CHCR. Dev Biol 2002, 250:218-230

41. Ebralidze A, Wang Y, Petkova V, Ebralidse K, Junghans RP: RNA leaching of transcription factors disrupts transcription in myotonic dystrophy. Science 2004, 303:383-387

42. Pascual M, Vicente M, Monferrer L, Artero R: The Muscleblind family of proteins: an emerging class of regulators of developmentally programmed alternative splicing. Differentiation 2006, 74:65-80

43. Nguyen TM, Morris GE: A rapid method for generating large numbers of high-affinity monoclonal antibodies from a single mouse. The Protein Protocols Handbook, 2nd Edition. Edited by Walker JM. Totowa NJ, Humana Press, 2002, pp. 1129-1138

44. Manilal S, Nguyen TM, Sewry CA, Morris GE: The Emery-Dreifuss muscular dystrophy protein, emerin, is a nuclear membrane protein Hum Mol Genet 1996, 5:801-808

45. Furling D, Lam le T, Agbulut O, Butler-Browne GS, Morris GE: Changes in myotonic dystrophy protein kinase levels and muscle development in congenital myotonic dystrophy. Am J Pathol 2003, 162:1001-1009

46. Morris GE, Cartwright AJ: Monoclonal antibody studies suggest a catalytic site at the interface between domains in creatine kinase. Biochim Biophys Acta 1990, 1039:318-322

47. Wilkinson FL, Nguyen TM, Manilal SB, Thomas P, Neal JW, Harper PS, Jones AL, Morris GE: Localization of rabbit huntingtin using a new panel of monoclonal antibodies. Brain Res Mol Brain Res 1999 69:10-20

48. Furling D, Coiffier L, Mouly V, Barbet JP, St Guily JL, Taneja K, Gourdon G, Junien C, Butler-Browne GS: Defective satellite cells in congenital myotonic dystrophy. Hum Mol Genet 2001, 10:2079-2087

49. Barbet JP, Thornell LE, Butler-Browne GS: Immunocytochemical characterisation of two generations of fibers during the development of the human quadriceps muscle. Mech Dev 1991, 35:3-11

50. Jiang H, Mankodi A, Swanson MS, Moxley RT, Thornton CA: Myotonic dystrophy type 1 is associated with nuclear foci of mutant RNA, sequestration of muscleblind proteins and deregulated alternative splicing in neurons. Hum Mol Genet 2004, 13:3079-3088

51. Vicente M, Monferrer L, Poulos MG, Houseley J, Monckton DG, O'Del KM, Swanson MS, Artero RD: Muscleblind isoforms are functionally distinct and regulate alpha-actinin splicing. Differentiation 2007, 75:427-440

52. Huang H, Wahlin KJ, McNally M, Irving ND, Adler R: Developmenta regulation of muscleblind-like (MBNL) gene expression in the chicken embryo retina. Dev Dyn 2008, 237:286-296

53. Hao M, Akrami K, Wei K, De Diego C, Che N, Ku JH, Tidball J, Graves MC, Shieh PB, Chen F: Muscleblind-like $2(\mathrm{Mbnl2})$-deficient mice as a model for myotonic dystrophy. Dev Dyn 2008, 237:403-410 